\title{
Changing parents' oral health knowledge and habits within an oral health promotion program for preschool children
}

\section{Peter Bakardjiev}

Assistant Professor, Department of pediatric dental medicine Faculty of Dental Medicine, Medical University, Sofia

\begin{abstract}
Introduction:

Parents influence their children's oral health by creating norms of behaviour. Their contribution is in the training and monitoring of oral hygiene habits, as well as the dietary behaviour of their children. It has been established that the parents' oral health habits and knowledge have an impact on the oral health status of their children.
\end{abstract}

\section{Material and methods:}

150 parents of children from the experimental group undergoing the dental health promotion program took part in the study. During the program, didactic trainings for the parents were organized in the course of three weeks.

\section{Aim:}

The aim of the study was to establish the changes in the parents' knowledge and skills regarding oral hygiene procedures, dietary habits and visits to the dentist in the course of the dental health promotion program for preschool children. 


\section{Results and discussion:}

As a result of the trainings for parents carried out as part of the dental health promotion program for preschool children, significant improvement of own knowledge and changes in oral hygiene habits, healthy eating habits and visits to the dentist were observed.

\section{Conclusion:}

The findings showed the need for applying didactic methods to improve parents' knowledge and habits. Due to the decisive factor they represent in developing proper oral health behavior of their children, it can be concluded that by using their own correct knowledge, they can achieve positive oral health results in their children more easily.

\section{Keywords: promotion, parents, preschool age}

\section{Introduction}

At the core of oral health promotion is the need for changes in the individual's knowledge, motivation and behavior in order to improve health and prevent diseases. Early childhood is the time when most habits are established for life (1). It offers the greatest opportunity to prevent diseases, which in turn can contribute for better health in adulthood (2). Good oral health behavior during childhood leads to better oral health in later years (3).

Parents influence their children's oral health by providing a favorable home environment, establishing norms of behavior and serving as role models. Their contribution lies in the training and monitoring of oral hygiene habits, as well as the dietary behavior of their children. They should be convinced in the importance of oral diseases' consequences and the possibilities they have to prevent these consequences $(4,5)$. It has been established that the parents' oral health habits and knowledge impact their children's health status $(6,7,8)$. That is why the educational approach should be directed to both the children and their parents $(9,10)$.

\section{Materials and methods}

150 parents of children from the experimental group undergoing the dental health promotion program took part in the study. During the program, didactic trainings for the parents were organized in the course of three weeks. The first week, a one-hour theoretical training on the causes of oral diseases was carried out. The second week - a 30-minute training on how oral hygiene procedures are conducted, means and methods; and the third week - a one-hour training on nutritional prophylaxis of dental caries. The trainings were carried out in the kindergartens which participated in the experiment.

In order to establish the initial knowledge and that at the end of the one-year experimental period on oral hygiene, diet and visits to the dentist, the following survey questionnaire was designed: 


\section{Table 1 Questionnaire for parents}

1. When do you brush your teeth?

a. In the morning / evening

b. In the morning and in the evening

2. How many times do you advise your children to brush their teeth?
a. Once
b. Twice

3. How long do you brush your teeth for?
a. One minute
b. Two minutes
c. More than two minutes

4. How long do you advise your children to brush their teeth for?
a. Less than two minutes
b. Two minutes
c. More than two minutes

5. Do you observe any sequence when brushing your teeth?
a. Yes
b. No

6. Do you help your child brush their teeth?
a. I monitor without helping
b. I monitor and I help
c. I monitor from time to time
d. I do not monitor

7. Do you allow your child snacks between meals?
a. Yes
b. No

8. What snacks do you allow your children between meals?
a. Sandwich
b. Sweets
c. Fruit

9. Do you take your child with you when you go to the dentist?
a. Always
b. Rarely
c. No

\section{Aim:}

The aim of the study was to determine the changes in parents' knowledge and skills regarding oral hygiene procedures, dietary habits and visits to the dentist in the course of the dental health promotion program for preschool children. 


\section{Results and discussion:}

Table 2. Tooth brushing frequency

\begin{tabular}{|l|c|c|c|c|c|c|}
\hline \multicolumn{1}{|c|}{ Time } & \multicolumn{2}{|c|}{ Once a day } & \multicolumn{2}{c|}{$\begin{array}{c}\text { Mornings and } \\
\text { evenings }\end{array}$} & \multicolumn{2}{c|}{} \\
\cline { 2 - 7 } & Number & $\%$ & Number & $\%$ & $\begin{array}{c}\text { Total } \\
\text { number }\end{array}$ & $\%$ \\
\hline Before & 33 & $22 \%$ & 117 & $78 \%$ & 150 & $100 \%$ \\
\hline After & 9 & $6 \%$ & 141 & $94 \%$ & 150 & $100 \%$ \\
\hline T, $\mathbf{p}$ & \multicolumn{2}{|c|}{$T=1.49, \mathrm{p}>0.05$} & \multicolumn{2}{|c|}{$T=3.71, \mathrm{p}<0.001$} & & \\
\hline
\end{tabular}

The above table shows the data on tooth brushing frequency for the parents. The results obtained prior to the study show that more than one fifth of the parents (22\%) of the studied children brush their teeth only once a day. The parents' lack of knowledge and proper behavior is a prerequisite for poor brushing behavior of children. After the implementation of the parents' training and motivation program, significant decrease can be seen of those brushing their teeth only once a day, as well as significant increase of those who adopted the right way of brushing their teeth twice a day, in the morning and in the evening.

Table 3. When they advise their children to brush their teeth

\begin{tabular}{|c|c|c|c|c|c|c|}
\hline \multirow{2}{*}{ Time } & \multicolumn{2}{|c|}{ Morning or evening } & \multicolumn{2}{|c|}{ Morning and evening } & \multirow{2}{*}{$\begin{array}{c}\text { Total } \\
\text { number }\end{array}$} & \multirow[t]{2}{*}{$\%$} \\
\hline & number & $\%$ & number & $\%$ & & \\
\hline Before & 31 & $20.67 \%$ & 119 & $79.33 \%$ & 150 & $100 \%$ \\
\hline After & 16 & $10.67 \%$ & 134 & $89.33 \%$ & 150 & $100 \%$ \\
\hline $\mathbf{T}, \mathbf{p}$ & \multicolumn{2}{|c|}{$\mathrm{T}=0.94, \mathrm{p}>0.05$} & \multicolumn{2}{|c|}{$\mathrm{T}=2.22, \mathrm{p}>0.05$} & & \\
\hline
\end{tabular}

The above table shows the results regarding parental control on tooth brushing frequency before and after the experiment. Before the experiment, $20.67 \%$ of parents advised their children to brush their teeth once a day. This is comparable to the number of parents who also brush their teeth once a day. It is obvious that parents raise their children relative to their own knowledge and habits. After the experiment, significantly more parents started to advise their children to brush their teeth twice a day. 
Table 4. Tooth brushing duration

\begin{tabular}{|c|c|c|c|c|c|c|c|c|}
\hline \multirow{2}{*}{ Time Duration } & \multicolumn{2}{|c|}{$<2 \min$} & \multicolumn{2}{|c|}{$2 \min$} & \multicolumn{2}{|c|}{$>2 \min$} & \multirow[b]{2}{*}{$\begin{array}{c}\text { Total } \\
\text { number }\end{array}$} & \multirow[b]{2}{*}{$\%$} \\
\hline & number & $\%$ & number & $\%$ & number & $\%$ & & \\
\hline Before & 28 & $18.66 \%$ & 88 & $58.67 \%$ & 34 & $22.67 \%$ & 150 & $100 \%$ \\
\hline After & 10 & $6.67 \%$ & 60 & $40 \%$ & 80 & $53.33 \%$ & 150 & $100 \%$ \\
\hline$T, p$ & \multicolumn{2}{|c|}{$T=1.11, p>0.05$} & \multicolumn{2}{|c|}{$\mathrm{T}=2.27, \mathrm{p}<0.01$} & \multicolumn{2}{|c|}{$\mathrm{T}=3.37, \mathrm{p}<0.01$} & & \\
\hline
\end{tabular}

Tooth brushing duration is the other significant element of oral hygiene habits. Results show that before the beginning of the experiment, a little more than half the parents brushed their teeth for about two minutes $-58.67 \%$. A duration of more than two minutes, which would ensure the required quality of brushing, can be found in only about one fifth of the parents. In addition, there is a group of parents $18.66 \%$ - who brush their teeth for less than 2 minutes, which speaks of a completely ineffective oral hygiene habit. After the completion of the experiment, a significant decrease was established of those who brush their teeth for less than two minutes $-6.67 \%$. There is a significant decrease in the number of parents who brush their teeth for two minutes and a significant increase of those who started to brush their teeth for more than two minutes.

Table 5. Duration recommended to children

\begin{tabular}{|c|c|c|c|c|c|c|c|c|}
\hline \multirow{2}{*}{$\begin{array}{l}\text { Duration } \\
\text { Time }\end{array}$} & \multicolumn{2}{|c|}{$<2 \min$} & \multicolumn{2}{|c|}{$2 \min$} & \multicolumn{2}{|c|}{$>2 \min$} & \multirow[b]{2}{*}{$\begin{array}{c}\text { Total } \\
\text { number }\end{array}$} & \multirow[b]{2}{*}{$\%$} \\
\hline & Number & $\%$ & Number & $\%$ & Number & $\%$ & & \\
\hline Before & 26 & $17.33 \%$ & 86 & $57.33 \%$ & 38 & $25.34 \%$ & 150 & $\begin{array}{c}100 \\
\%\end{array}$ \\
\hline After & 6 & $4 \%$ & 60 & $40 \%$ & 84 & $56 \%$ & 150 & $\begin{array}{c}100 \\
\%\end{array}$ \\
\hline$T, p$ & $\mathrm{~T}=1.22$ & $>0.05$ & $\mathrm{~T}=2.09$ & $<0.01$ & $\mathrm{~T}=3.44$, & $<0.001$ & & \\
\hline
\end{tabular}

The results in the above table show that parents' recommendations on the duration of tooth brushing once again correspond to their own knowledge and habit. More than half the parents recommend to their children to brush their teeth for two minutes, and $17.33 \%$ - to brush their teeth for less than two minutes. Their own behavior is similar. After the completion of the experiment, a decrease can be seen in the 
number of parents recommending brushing for less than two minutes to their children. There is a significant decrease in the number of those who recommend a duration of two minutes and a significant increase of those recommending more than two minutes. Here we can see the result of motivation stemming from the parents' training.

Table 6. Sequence in tooth brushing

\begin{tabular}{|c|c|c|c|c|c|c|}
\hline \multirow{2}{*}{$\mathrm{P}_{\text {Time }}$ Sequence } & \multicolumn{2}{|c|}{ Yes } & \multicolumn{2}{|c|}{ No } & \multirow[t]{2}{*}{ Total number } & \multirow[b]{2}{*}{$\%$} \\
\hline & Number & $\%$ & Number & $\%$ & & \\
\hline Before & 129 & $86 \%$ & 21 & $14 \%$ & 150 & $100 \%$ \\
\hline After & 141 & $94 \%$ & 9 & $6 \%$ & 150 & $100 \%$ \\
\hline$T, p$ & \multicolumn{2}{|c|}{$\mathrm{T}=2.19, \mathrm{p}<0.01$} & \multicolumn{2}{|c|}{$\mathrm{T}=0.73, \mathrm{p}>0.05$} & & \\
\hline
\end{tabular}

It can be seen from the above table that most parents observed some kind of sequence in tooth brushing at the start. Still, there are $14 \%$ of parents who do not observe one. These parents would not be able to help their children create a habit for tooth brushing sequence, which increases the risk of some teeth remaining uncleaned. After the completion of the experiment, a significant increase was established in the number of parents who now observe such a sequence.

Table 7. Participation in children's tooth brushing

\begin{tabular}{|c|c|c|c|c|c|c|c|c|c|c|}
\hline \multirow[t]{2}{*}{$\begin{array}{l}\text { Rarticipation } \\
\text { Time }\end{array}$} & \multicolumn{2}{|c|}{$\begin{array}{l}\text { Monitor, but } \\
\text { do not help }\end{array}$} & \multicolumn{2}{|c|}{$\begin{array}{c}\text { Monitor and } \\
\text { help }\end{array}$} & \multicolumn{2}{|c|}{$\begin{array}{c}\text { Sometimes } \\
\text { monitor }\end{array}$} & \multicolumn{2}{|c|}{ Do not monitor } & \multirow[b]{2}{*}{$\begin{array}{c}\text { Total } \\
\text { no. }\end{array}$} & \multirow[b]{2}{*}{$\%$} \\
\hline & No. & $\%$ & No. & $\%$ & No. & $\%$ & No. & $\%$ & & \\
\hline Before & 25 & $\begin{array}{c}16.67 \\
\%\end{array}$ & 88 & $\begin{array}{c}58.67 \\
\%\end{array}$ & 32 & $\begin{array}{c}21.33 \\
\%\end{array}$ & 5 & $3.33 \%$ & 150 & $100 \%$ \\
\hline After & 13 & $8.67 \%$ & 114 & $76 \%$ & 20 & $\begin{array}{c}13.33 \\
\%\end{array}$ & 3 & $2 \%$ & 150 & $100 \%$ \\
\hline $\mathrm{T}, \mathrm{p}$ & & $\begin{array}{l}.74 \\
.05\end{array}$ & & & & & & & & \\
\hline
\end{tabular}

Exercising control on tooth brushing is a serious prerequisite for developing the right oral hygiene habits in children. The findings show that a little more than half the parents monitor and help with the procedure. The other groups, however, demonstrate a lack of interest in how the procedure is performed, which leads to preconditions for improper and inefficient tooth brushing in children. After the completion of the experiment, a significant increase can be seen in parents who started to monitor and help their children. 
The other field of impacting parental behavior is developing proper eating habits. Two questions were asked - existence of snacking and its nature.

Table 8. Allowing snacks between meals

\begin{tabular}{|l|c|c|c|c|c|c|}
\hline \multirow{2}{*}{ Time } & \multicolumn{2}{|c|}{ Yes } & \multicolumn{2}{c|}{ No } & \multirow{2}{*}{$\begin{array}{c}\text { Total } \\
\text { number }\end{array}$} & $\%$ \\
\cline { 1 - 5 } Before & Number & $\%$ & Number & $\%$ & 150 & $100 \%$ \\
\hline After & 125 & $83.33 \%$ & 25 & $16.67 \%$ & 150 & $100 \%$ \\
\hline T, p & 79 & $52.67 \%$ & 71 & $47.33 \%$ & & \\
\hline
\end{tabular}

The preliminary survey of parents shows that those who allow snacks between meals are the majority 83.33\%. After completion of the experiment, a significant decrease is observed in that group of parents, as well as a significant increase of those who no longer allow snacks between meals.

Table 9. Type of snacks allowed

\begin{tabular}{|c|c|c|c|c|c|c|c|c|}
\hline & \multicolumn{2}{|c|}{ Sandwich } & \multicolumn{2}{|c|}{ Sweets, chips } & \multirow{2}{*}{$\begin{array}{l}\text { Fruit } \\
\text { No. }\end{array}$} & \multirow[b]{2}{*}{$\%$} & Total & $\%$ \\
\hline & No. & $\%$ & No. & $\%$ & & & \multirow[b]{2}{*}{150} & \multirow[b]{2}{*}{$100 \%$} \\
\hline Before & 31 & $20.67 \%$ & 94 & $62.67 \%$ & 25 & $16.67 \%$ & & \\
\hline After & 32 & $21.33 \%$ & 50 & $33.33 \%$ & 68 & $45.34 \%$ & 150 & $100 \%$ \\
\hline$T, p$ & \multicolumn{2}{|c|}{$\mathrm{T}=0.73, \mathrm{p}>0.05$} & \multicolumn{2}{|c|}{$T=3.52, p<0.001$} & \multicolumn{2}{|c|}{$\mathrm{T}=2.78, p<0.01$} & & \\
\hline
\end{tabular}

In order to establish the seriousness of the risk of caries development created by snacking between meals, parents were asked about the type of snacks. Initial results showed that more than half the parents allow sweets as snacks, which presents a serious risk of dental caries development. Very few give fruit as snacks. After the experiment, a significant decrease can be observed in the parents who allow their children different types of sweets between meals. This proves a reduction of the risk of caries development. At the same time, there is a significant increase of fruit intake, which is the significantly better option for snacking, also providing children with the vitamins they need.

The third field of change in the parents' attitude towards their children's oral health is the attitude to dental treatment and visits to the dentist's office, which would also create an opportunity for control, timely treatment and prevention. 
Table 10. Visits to the dentist together with the children

\begin{tabular}{|c|c|c|c|c|c|c|c|c|}
\hline \multirow{2}{*}{ Time } & \multicolumn{2}{|c|}{ Always } & \multicolumn{2}{|c|}{ Rarely } & \multicolumn{2}{|c|}{ No } & \multirow[b]{2}{*}{$\begin{array}{c}\text { Total } \\
\text { number }\end{array}$} & \multirow[b]{2}{*}{$\%$} \\
\hline & Number & $\%$ & Number & $\%$ & Number & $\%$ & & \\
\hline Before & 3 & $2 \%$ & 51 & $34 \%$ & 96 & $64 \%$ & 150 & $100 \%$ \\
\hline After & 14 & $9.33 \%$ & 73 & $48.67 \%$ & 63 & $42 \%$ & 150 & $100 \%$ \\
\hline$T, p$ & \multicolumn{2}{|c|}{$T=0.65, p>0.05$} & \multicolumn{2}{|c|}{$T=1.65, p>0.05$} & \multicolumn{2}{|c|}{$\mathrm{T}=2.78, \mathrm{p}<0.01$} & & \\
\hline
\end{tabular}

The first question to the parents was whether they take their children with them when they go to the dentist. That would be a good way to familiarize children with the environment and the need for regular visits. Thus the child would be prepared for future visits and perceive dental treatment as natural and necessary. Before the study, it can be seen that only $2 \%$ of parents do that. All the rest did not use this as a way to prepare the child. After the experiment, a significant decrease can be observed in cases when they do not. An increase can be seen in the share of parents who take the children with them to the dentist, but no significant difference was established. There is an increase in the number of parents who started to take their children with them, but again no significant difference was established. It is obvious that this measure, which has to do with time requirements and possibility is more difficult to manifest. Still, it is positive that there is a decrease in the number of parents who have never done this.

\section{Discussion}

In the course of the oral health promotion program, a statistically significant positive impact was established on the parents' oral hygiene knowledge, dietary behavior and visits to the dentist. As a result of the developed own motivation and acquired knowledge, they can exercise better control on their children's oral hygiene procedure. Similar results were found in the review of available literature $(11,12)$.

Motivation developed in the parents for a change in eating habits at home gradually changes their children's behavior. Similar observations on this issue can be found in literary sources $(13,14)$.

Involving parents in the oral health promotion program leads to more frequent and motivated visits to the dentist. This is also confirmed by publications in the field $(14,15)$.

\section{Conclusion:}

Involving parents in the oral health promotion program for preschool children leads to significant enhancement of their knowledge and improves their habits. This in turn is a prerequisite for a better and more comprehensive change of the factors leading to their children's improved oral health. 


\section{References}

1. Oral Health Promotion Strategic Plan 2012-2017, Oral Health Services Tasmania. Available at: http://www.dhhs.tas.gov.aul

2. Heckman, JJ. Investing in Disadvantaged Young Children is Both Fair and Efficient. Presented to the Committee for Economic Development, the Pew Charitable Trusts, PNC Financial Services Group, New York City 2006.

3. Wind M, Kremers S, Thijs C, Brug J. Toothbrushing at school: effects on tooth brushing behaviour, cognitions and habit strength, Health education 2005;105:1:53-61.

4. Hartrick G. Developing health-promoting practice with families: one pedagogical experience. J Adv Nurs 2000;31:27-34.

5. World Health Organization. Information Series On School Health, Document Eleven. Oral Health Promotion: An Essential Element of a Health-Promoting School. Geneva: WHO, 2003.

6. Action plan for oral health promotion 2013-2017. State of Victoria, Department of Health 2013. Available at: http://docs.health.vic.gov.au/docs/doc/Action-plan-for-oral-health-promotion-2013$\underline{2017}$

7. Mattila ML, Rautava $P$, Ojanlatva A, Paunio P, Hyssälä L, Helenius $H$, et al. Will the role of family influence dental caries among seven-year-old children? Acta Odontol Scand 2005;63:2:73-84.

8. Mattila ML, Rautava $P$, Sillanpää M, Paunio $P$. Caries in five-year-old children and associations with family-related factors. J Dent Res 2000;79: 875-881.

9. Efe E, Sarvan S, Kukulu K. Self-reported knowledge and behaviors related to oral and dental health in Turkish children. Issues Compr Pediatr Nurs 2007;30:4:133-46.

10. Blinkhorn AS, Wainwright-Stringer YM, Holloway PJ. Dental health knowledge and attitudes of regularly attending mothers of high-risk, pre-school children. Int Dent J 2001;51:6:435-438.

11. Arrow $P$, Raheb J, Miller $M$. Brief oral health promotion intervention among parents of young children to reduce early childhood dental decay. BMC Public Health 2013 Mar 20;13:245.

12. Weinstein P, Harrison R, Benton T. Motivating mothers to prevent caries: confirming the beneficial effect of counselling. J Am Dent Assoc 2006;137:789-793.

13. Duijster D, de Jong-Lenters M, Verrips E, et al. Establishing oral health promoting behaviours in children - parents' views on barriers, facilitators and professional support: a qualitative study. BMC Oral Health 2015;10:15:157.

14. Duijster D, Verrips GHW, van Loveren C. The role of family functioning in childhood dental caries. Community Dent Oral Epidemiol 2014;42:193-205.

15. Huebner CE, Riedy CA. Behavioral determinants of brushing young children's teeth: implications for anticipatory guidance. Pediatr Dentist 2010;32:48-55.

\section{Corresponding author:}

\section{Dr. Peter Bakardjiev DM}

Faculty of dental medicine,

Medical university Sofia,

Department of pediatric dental medicine

1431, 1 G.Sofiiski str.

Sofia, Bulgaria

email: bucki_tuz@yahoo.com 